\title{
BMJ Open Feasibility of allied health assistant management of people with acute hip fracture: protocol for a feasibility randomised controlled trial
}

\author{
David A Snowdon (D , ${ }^{1,2}$ Peggy Vincent, ${ }^{3}$ Michele L Callisaya, ${ }^{1,2}$ Taya A Collyer, ${ }^{1}$ \\ Yi Tian Wang, ${ }^{3}$ Nicholas F Taylor (i) ${ }^{4,5}$
}

To cite: Snowdon DA, Vincent $P$, Callisaya ML, et al. Feasibility of allied health assistant management of people with acute hip fracture: protocol for a feasibility randomised controlled trial. BMJ Open 2021;11:e054298. doi:10.1136/ bmjopen-2021-054298

- Prepublication history and additional supplemental material for this paper are available online. To view these files, please visit the journal online (http://dx.doi.org/10.1136/ bmjopen-2021-054298).

Received 08 June 2021 Accepted 02 November 2021

\section{Check for updates}

(c) Author(s) (or their employer(s)) 2021. Re-use permitted under CC BY-NC. No commercial re-use. See rights and permissions. Published by BMJ.

${ }^{1}$ Peninsula Clinical School, Central Clinical School, Monash University, Frankston, Victoria, Australia

${ }^{2}$ Academic Unit, Peninsula Health, Frankston, Victoria, Australia

${ }^{3}$ Physiotherapy Department, Peninsula Health, Frankston, Victoria, Australia

${ }^{4}$ College of Science Health and Engineering, La Trobe University, Melbourne, Victoria, Australia ${ }^{5}$ Allied Health Clinical Research Office, Eastern Health, Box Hill, Victoria, Australia

Correspondence to

Dr David A Snowdon;

david.snowdon@monash.edu

\section{ABSTRACT}

Introduction Guidelines for hip fracture care state that patients with hip fracture should be mobilised on the day after surgery and at least once a day thereafter. However, compliance with these guidelines is poor. One approach that would assist physiotherapists to meet mobility guidelines after hip fracture is to delegate the provision of daily mobilisation to allied health assistants under their supervision. Therefore, we plan to conduct a randomised controlled trial to determine the feasibility of an allied health assistant providing daily inpatient rehabilitation to patients with hip fracture.

Methods and analysis Using a parallel group randomised controlled design with one-to-one allocation, participants will be randomly allocated to an experimental group (allied health assistant management) or a comparison group (physiotherapist management). Inclusion criteria are: adult with diagnosis of hip fracture; inpatient in acute hospital; walked independently pre-hip fracture and able to communicate in conversational English. The experimental group will receive routine physiotherapy rehabilitation, including daily mobilisation, from an allied health assistant following initial physiotherapist assessment. The comparison group will receive routine rehabilitation from a physiotherapist. The primary outcome will be the feasibility of allied health assistant management of patients with hip fracture. Feasibility will be determined using the following areas of focus in Bowen's feasibility framework: acceptability (patient satisfaction), demand (proportion of patients who participate), implementation (time allied health assistant/physiotherapist spends with participant, occasions of service) and practicality (cost, adverse events). Staff involved in the implementation of allied health assistant care will be interviewed to explore their perspectives on feasibility. Secondary outcomes include compliance with daily mobilisation guidelines, discharge destination, hospital readmission, falls, functional activity and length of stay. We aim to recruit 50 participants. Descriptive statistics will be used to describe feasibility and mobilisation rates will be calculated using Cox proportional hazards regression to compare compliance with mobilisation guidelines.

Ethics and dissemination Ethics approval was obtained from the Peninsula Health human research ethics committee (HREC/63 005/PH-2020). The findings will be disseminated in peer-reviewed journals and conference presentations.
Strengths and limitations of this study

- This trial will investigate the feasibility of allied health assistant management of people with hip fracture in the acute hospital environment using Bowen et al's framework.

- The impact of allied health management of people with hip fracture on patient (eg, compliance with daily mobilisation guidelines), staff (eg, acceptability of allied health assistant management of hip fracture) and organisational outcomes (eg, length of stay, cost) will be investigated.

- As this is a feasibility study, we cannot determine whether allied health assistant care is equivalent or non-inferior to physiotherapist care.

- Neither participants nor staff will be blind to group allocation, which may affect participants' responses to the intervention received and may lead to differential use of supplemental care by staff members.

- Participants will be randomised individually, which introduces a risk of contamination bias that will be monitored in this feasibility trial

Trail registration number Australian and New Zealand Clinical Trial Registry; ACTRN12620000877987; Preresults.

\section{INTRODUCTION}

Hip fractures have serious consequences for 23000 Australians who fracture their hip each year. ${ }^{1}$ Mortality rates at 12 months are in excess of $20 \% .^{23}$ For survivors, only $65 \%$ will return to living at home and $45 \%$ to their prefracture level of walking. ${ }^{24}$ Guidelines for hip fracture care recommend people with hip fracture should mobilise (ie, transfer out of bed and walk away from the bedside) on the day after surgery and at least once a day thereafter. ${ }^{56}$ However, compliance with these guidelines is poor with only $6 \%-14 \%$ of patients mobilising daily over the first five postoperative days. ${ }^{7}$ This has implications for people recovering from hip fracture surgery, 
as increased compliance with hip fracture guidelines is associated with lower mortality and readmission rates and a twofold increase in the odds of hospital discharge by 30 days postoperatively. ${ }^{89}$

Initiatives such as direct clinical supervision of physiotherapists during provision of hip fracture care have improved the proportion of patients who mobilise on the day after surgery (ie, early mobilisation rates) but have had little impact on mobilisation rates thereafter (ie, daily mobilisation). ${ }^{7}$ This is concerning as people with hip fracture are known to have very low levels of physical activity during their acute hospital stay and more frequent mobilisation has been shown to improve independence with functional tasks and reduce length of hospital stay following hip fracture. ${ }^{10} 11$ One possible explanation is that strategies have targeted behaviour change in physiotherapists, whose focus is to provide assessment and discharge planning in acute hospital. ${ }^{12-14}$ The need for high patient throughput in this setting means physiotherapists have limited time to provide rehabilitation following initial assessment/mobilisation and initiatives aimed at behaviour change will likely have limited impact on daily mobilisation rates.

An alternative approach is to delegate the provision of daily mobilisation to allied health assistants under the supervision of a physiotherapist. Allied health assistants are support staff who complete clinical and non-clinical tasks under the supervision and delegation of an allied health professional. ${ }^{15} 16$ The role of an allied health assistant often complements the work of the allied health professionals and assists in the delivery of allied health services across a broad range of clinical settings, including the acute hospital setting. ${ }^{12}$ In general, allied health assistants do not perform clinical duties that involve evaluation, diagnosis or assessment of patient health conditions. ${ }^{16-19}$ Instead, they primarily focus on rehabilitation and providing therapy prescribed by allied health professionals to patients. Allied health assistants are also referred to as physical therapy aides or physiotherapy assistants and work in the Australian, New Zealand, UK and North American healthcare systems. ${ }^{20}$

Given that allied health assistants' primary role is to provide delegated therapy, they may have greater impact on daily mobilisation rates of people with hip fracture than physiotherapists who are constrained by the demands of their role in facilitating patient flow through assessment and discharge processes. ${ }^{1318}$ In addition, delegating routine, guideline-directed care to allied health assistants should create more capacity for physiotherapists to perform the more specialised components of their role (ie, assessment and prescription of therapy) to more patients. ${ }^{17}{ }^{21}$ However, it is important that both safety and effectiveness are considered when substituting physiotherapist led care with allied health assistant care. ${ }^{20}$

Therefore, prior to conducting a large-scale randomised controlled trial (RCT) to determine whether allied health assistant care is equivalent or non-inferior to care provided by physiotherapists, the primary aims of this feasibility
RCT are to (1) determine the feasibility of allied health assistant management of people with hip fracture in the acute hospital environment and (2) provide an estimate of the effect of the model of care on compliance with daily mobilisation guidelines and outcomes after surgery. Feasibility will be determined using Bowen $e t a l$ 's framework and will include assessment of the following areas: acceptability, demand, implementation and practicality. ${ }^{22}$

The secondary aims are to estimate the effect of allied health assistant management of patients with hip fracture on (1) patient outcomes (compliance with daily mobilisation guidelines, discharge destination, hospital readmission, falls, functional activity) and (2) organisational outcomes (length of stay, cost).

\section{METHODS AND ANALYSIS \\ Trial design}

A feasibility RCT will be conducted in an orthopaedic ward at a publicly funded acute hospital in Melbourne, Australia. Allied health assistant care will be compared with usual physiotherapy management of patients with hip fracture where the allied health assistant does not have responsibility for the daily mobilisation or routine rehabilitation of patients with hip fracture.

Staff who are involved in the implementation of allied health assistant management of patients with hip fracture (ie, allied health assistants, physiotherapists and physiotherapy manager) will be interviewed to help establish staff perspectives on the feasibility of the intervention.

\section{Study setting}

The trial will be conducted at a 450 bed publicly funded tertiary hospital that provides acute healthcare services to the Mornington Peninsula in Victoria, Australia. The local government area has a population of approximately 155 000 people of whom $52 \%$ are women and the median age is 46 years with $25 \%$ of the population aged $\geq 65$ years. ${ }^{23}$ The percentage of people living with profound disability is $4 \%, 11 \%$ for those aged $\geq 65$ years and $5 \%$ need assistance with core activities of daily living. ${ }^{24}$

\section{Randomisation and allocation procedure}

Participants will be randomised to either allied health assistant or usual physiotherapy care. Participants will be assigned remotely, using a simple randomisation design, by consulting an allocation sequence established at the beginning of recruitment. This sequence will be prepared using a computer random number generator, by a member of the research team who is not involved in recruitment, patient management or assessment. Allocation will be determined by email contact with the research team member after the participant has been determined eligible for participation and has consented to take part in the study. The allocation sequence will remain concealed throughout enrolment and assignment. All participants will be required to provide written, informed consent prior to randomisation. Due to the 
nature of the interventions, participants, physiotherapists and allied health assistants cannot be blind to the treatment allocation.

\section{Participants}

Patient participants' eligibility criteria

Eligible participants will be patients who have undergone surgery for management of hip fracture. This includes patients who have undergone either hip joint replacement or internal fixation with screws/nails, as hip fracture clinical practice guidelines for mobilisation do not distinguish between surgical techniques. ${ }^{5}{ }^{6}$ Participants must meet the following eligibility criteria:

- Inpatient in acute hospital.

- Admission diagnosis of hip fracture (S72.0-S72.2 according to the International Classification of Diseases 10th revision (ICD-10).

- Walked independently prehip fracture with or without the use of a walking aid.

- Willingness and ability to participate in postoperative physiotherapy, as determined by initial physiotherapy assessment.

- Aged 18 years or older.

- Able to provide written, informed consent.

- Able to communicate in conversational English.

Exclusion criteria are:

- Unable to participate in physiotherapy rehabilitation/mobilisation (eg, patients with a postoperative lower extremity touch or non-weight bearing status).

- Non-ambulant or required assistance of another person to walk prehip fracture.

- Impaired cognition (Short Portable Mental Status Questionnaire Score $<8) .{ }^{25}$

If the patient is not appropriate for mobilisation, they will not be eligible for participation in the study. Mobilisation will be contraindicated if the patient experiences any of the following complications ${ }^{26-28}$ :

- Severe postoperative pain that restricts weight bearing.

- Nausea or vomiting with or without antimetic.

- Vitally unstable: postural blood pressure drop, febrile, bradycardia $<40 \mathrm{bpm}$ or abnormal heart rhythm.

- Disorientated, heavily sedated or difficult to rouse.

Participants assessed as not appropriate for mobilisation can be included in the study if their medical stability improves on any day during their admission.

Patients with hip fracture who were non-ambulant prior to the fracture cannot be expected to ambulate post hip fracture. Patients with hip fracture with either a nonweight bearing status or a touch weight bearing status will be excluded from the trial as these restrictions will limit their capacity to be mobilised, according to hip fracture clinical practice guidelines. ${ }^{56}$ Current guidelines recommend that patients are weight bearing with no restrictions postoperatively. ${ }^{56}$ Currently, $95 \%$ of patients are allowed to fully weight bear after hip fracture surgery. ${ }^{29}$ Patients scoring 8 or higher on the Short Portable Mental Status Questionnaire, indicating normal mental functioning, will be eligible to participate in the study to ensure that they can provide feedback on the allied health assistant model of care (ie, complete a satisfaction survey) ${ }^{25}$

\section{Staff participants eligibility criteria}

Staff participants for this trial include any allied health assistant, physiotherapist or manager involved in the implementation of the allied health assistant model of care in the participating ward. Staff choosing to participate in interviews will be required to provide written informed consent prior to participation.

\section{Recruitment}

A member of the research team will screen all patients admitted to the acute hospital with a diagnosis of hip fracture. Patients who are deemed appropriate for postoperative physiotherapy following initial physiotherapy assessment and management will be approached by a member of the research team, who will introduce the patient to the trial using a standardised script. Patients expressing interest will be provided with a participant information and consent form (online supplemental file 1). Recruitment will occur on the ward at the patient's bedside. Prior to gaining written, informed consent the patient's cognition will be screened by a member of the research team using the Short Portable Mental Status Questionnaire. $^{25}$

Eligible staff members will be invited via email to participate in qualitative semistructured interviews. Staff expressing interest will be contacted by a member of the research team who will explain the trial and gain written, informed consent prior to the interview (online supplemental file 2).

\section{Intervention}

The experimental group will receive routine acute physiotherapy rehabilitation from an allied health assistant (table 1). This will involve a senior allied health assistant with a certificate IV allied health assistant qualification (ie, highest level allied health assistant qualification in Australia) and at least 6 months prior experience working in an acute hospital setting, delivering routine postoperative physiotherapy rehabilitation to participants under the supervision of a registered physiotherapist.

Routine acute rehabilitation of patients with hip fracture should include guideline-recommended daily mobilisation (ie, walking) and may also include the following ${ }^{56}$ : progression of gait aid, standing or seated exercises and education (eg, correct use of gait aid, falls risk strategies, correct performance of exercises).

The allied health assistant will provide rehabilitation to participants following an initial postoperative physiotherapy assessment. This process will involve the physiotherapist completing an initial assessment, prescribing appropriate physiotherapy rehabilitation and providing a handover to the allied health assistant. ${ }^{30}$ All therapies will be tailored to the individual needs of patients and provided face-to-face on the acute orthopaedic ward. The aim of the intervention is to provide this therapy (ie, 
Table 1 Description of intervention and comparison group interventions according to the template for intervention description and replication

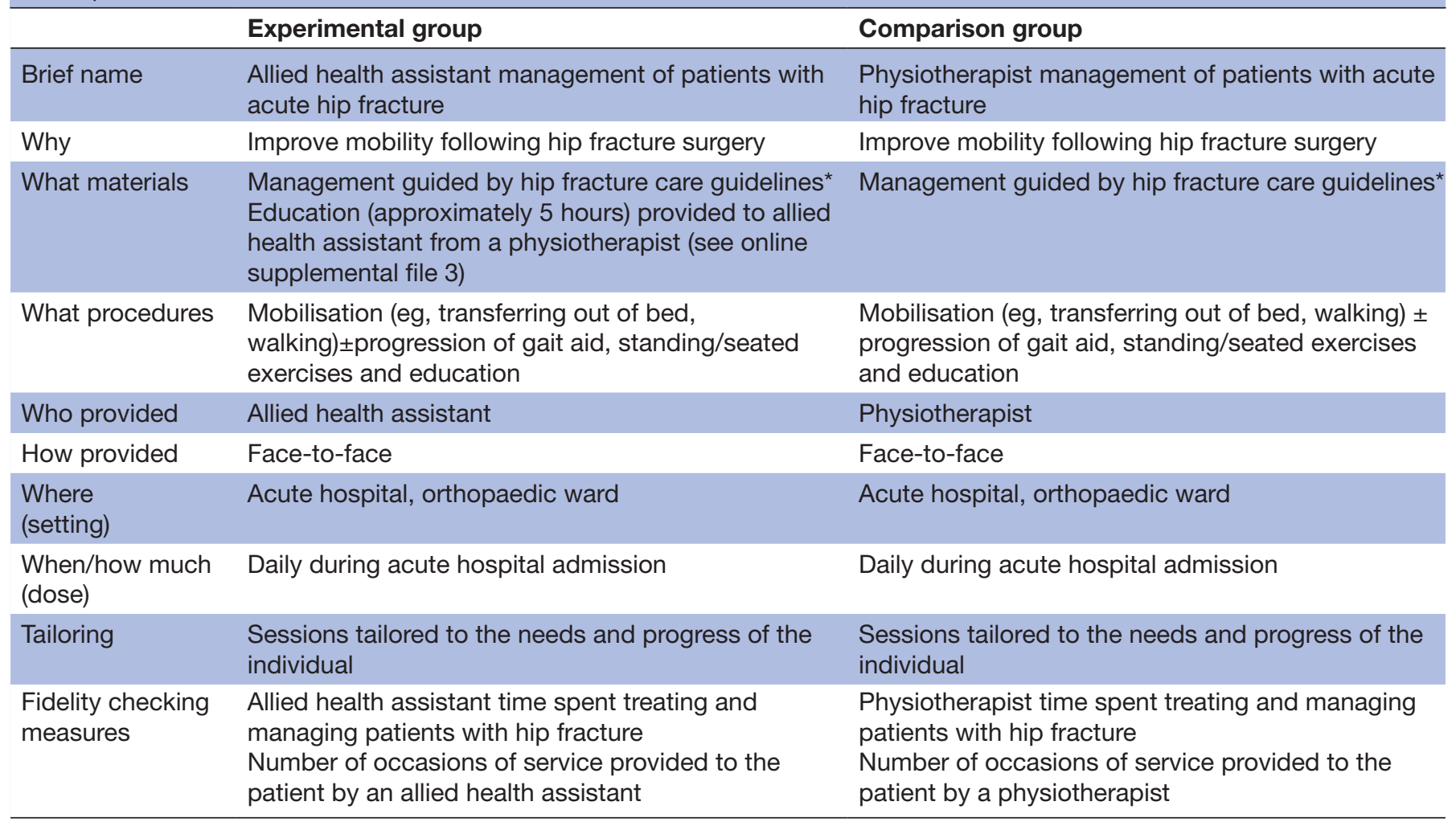

*Guidelines include (1) Australian and New Zealand Guideline for Hip Fracture Care and (2) National Clinical Guideline Centre Guideline for Management of Hip Fracture in Adults.

mobilisation) at least daily for the entirety of the acute hospital admission. ${ }^{56}$ Following each treatment session, the allied health assistant will inform the physiotherapist, who completed the initial assessment, of the details of the session and the participant's progress in their ability to mobilise. ${ }^{30}$ The physiotherapist will use this feedback to determine the discharge plan and reassess the patient as required. The allied health assistant can rerefer the patient back to the physiotherapist if the participant's condition changes during their hospital stay. ${ }^{26-28}$

The senior orthopaedic physiotherapist will supervise the allied health assistants in accordance with the health service's allied health clinical supervision guideline. ${ }^{31}$ This supervision will include monthly meetings to discuss professional and clinical skill development. The monthly supervision meetings may also involve direct supervision/ observation of allied health assistants' management of patients with hip fracture. ${ }^{7}$ The allied health assistants will also be educated on hip fracture management and rehabilitation prior to the commencement of the trial. The education will be provided by a senior orthopaedic physiotherapist and include tutorials and clinical exposure learning activities, totalling approximately 5 hours duration (online supplemental file 3).

Allied health assistant rehabilitation of patients with hip fracture will be compared with usual practice where a physiotherapist manages the postoperative acute rehabilitation of these patients (table 1). Allied health assistants may assist the therapist to mobilise a participant who requires the assistance of two people but will not be delegated the role of providing routine acute rehabilitation for participants randomised to the comparison group.

\section{Outcomes}

Outcomes for this study will be at the patient, staff and organisational level (table 2). Patient and organisational data will be routinely collected (ie, documented in patient medical records, and hospital incident reporting and costing data systems) with the exception of a patient satisfaction survey, which will be administered by an assessor blind to group allocation. Routinely collected data will be collated by a researcher also blind to group allocation. Staff data will consist of individual semistructured in-depth interviews with staff involved in the implementation of the allied health assistant model of care. Interviews will be approximately 30 min duration and guided by a semistructured interview guide (table 3). Four areas of focus in Bowen et al's framework were used to inform development of the interview guide: acceptability, demand, implementation and practicality. ${ }^{22}$ Following development, the interview guide was piloted on two allied health assistants who work in acute hospital settings and their feedback informed minor amendments to the 


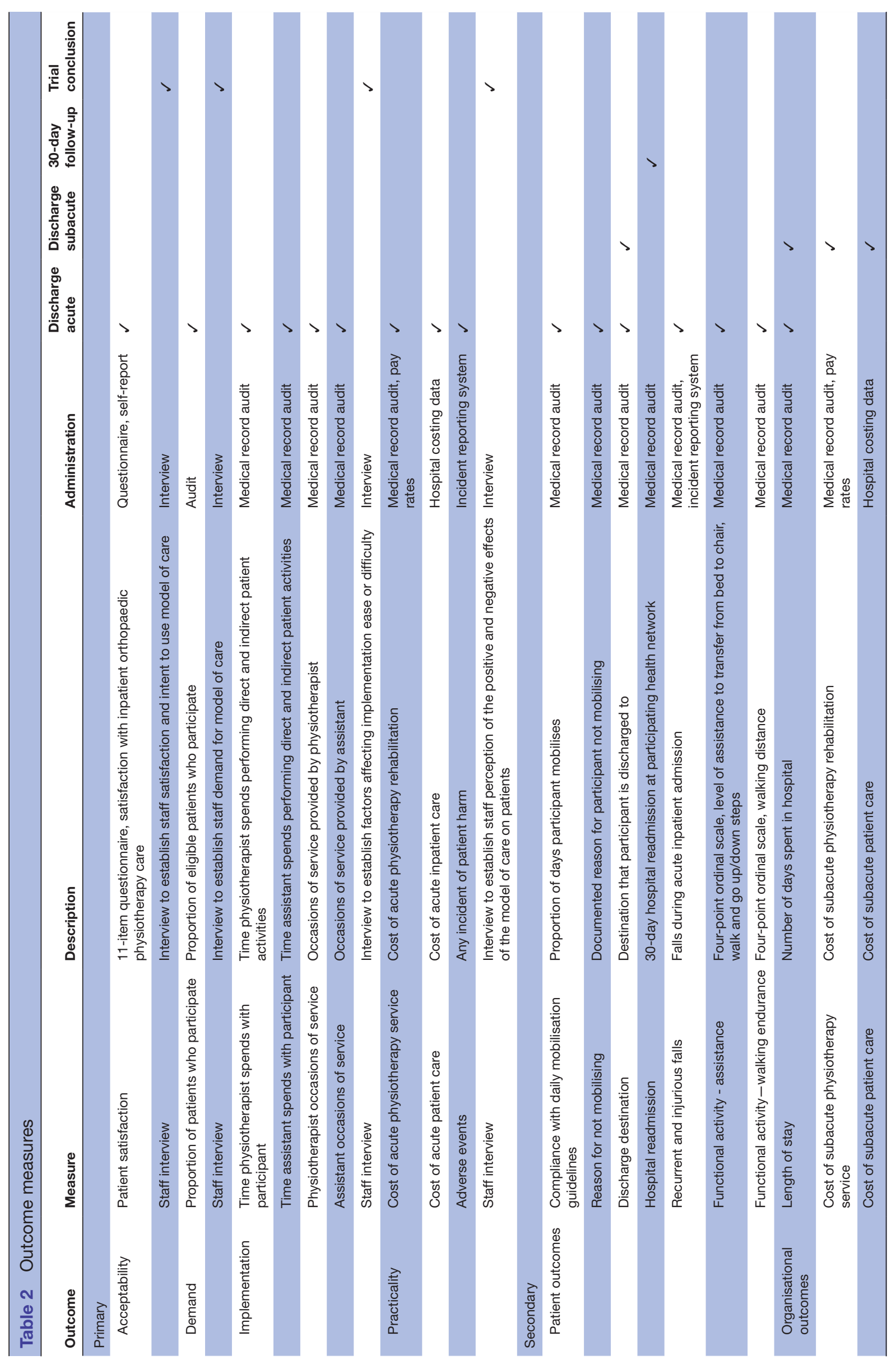


Table 3 Semi-structured interview guide

\begin{tabular}{lll}
\hline Topic & Sample question & Bowen et al $^{\mathbf{2 2}}$ area of focus \\
\hline Introduction & What is your role/position in the physiotherapy department? & Not applicable \\
& What is your previous experience in managing patients with hip Not applicable & fracture?
\end{tabular}

Role of allied health assistant Describe the role that the allied health assistant has in providing Practicality in hip fracture care and care to patients with hip fracture in this study? project outcomes

\begin{abstract}
Describe the outcomes for (i) patients and (ii) staff?
What were the benefits of the model of care?
\end{abstract}

What were the burdens of the model of care?

Describe any safety issues with the model of care for patients with hip fracture? How/why was this the case?
Practicality

Practicality

Practicality

Practicality

\begin{tabular}{|c|c|c|}
\hline \multirow[t]{4}{*}{$\begin{array}{l}\text { Implementation of allied } \\
\text { health assistant model of care }\end{array}$} & $\begin{array}{l}\text { Describe your experience with implementing the model of allied } \\
\text { health assistant care? }\end{array}$ & Implementation \\
\hline & $\begin{array}{l}\text { What were the barriers/challenges of implementing the model of } \\
\text { care? }\end{array}$ & Implementation \\
\hline & What were the facilitators of implementing the model of care? & Implementation \\
\hline & How could implementation of the model be improved? & Implementation \\
\hline \multirow[t]{4}{*}{$\begin{array}{l}\text { Future role of allied health } \\
\text { assistant model of care }\end{array}$} & $\begin{array}{l}\text { Would you like to continue to use this model of care for patients } \\
\text { with hip fracture? Why? }\end{array}$ & Acceptability/demand \\
\hline & Describe the sustainability of this model of care? & Acceptability/demand \\
\hline & $\begin{array}{l}\text { Do you think any changes should be made to the model of } \\
\text { care? }\end{array}$ & Acceptability/demand \\
\hline & $\begin{array}{l}\text { Tell me about whether this model of care be used in other health } \\
\text { settings or with other patient populations? }\end{array}$ & Acceptability/demand \\
\hline
\end{tabular}

wording of questions. Interviews will be audiotaped and transcribed verbatim. Each participant will be sent a copy of their transcript for correction, clarification and further comment, to maximise accuracy of the data (a process termed 'member checking'). ${ }^{32}$

\section{Primary outcome measure}

The primary outcome for this trial will be the feasibility of the allied health assistant management of patients with hip fracture. Feasibility will be determined using the following areas of focus in Bowen et al's framework for designing feasibility studies: acceptability, demand, implementation and practicality. ${ }^{22}$ All patient participant outcomes relating to feasibility will be measured at discharge from acute hospital. Staff participant interviews will be conducted at the conclusion of their involvement in the trial.

\section{Acceptability}

The following measures will be used to determine whether the allied health assistant model is suitable, satisfying or attractive to programme deliverers and recipients:

- Qualitative interview with staff members to establish staff satisfaction with model of care, perceived positive and negative effects on organisation, intent to continue use of model of care and perceived appropriateness of model of care (table 3).

- Patient satisfaction with physiotherapy care will be measured using a modified version of a previously established questionnaire for hospital inpatients receiving inpatient orthopaedic physiotherapy care. ${ }^{33}$ The original questionnaire consists of 17 items/statements on physiotherapy care. The patient rates their agreement with each statement on a 5-point Likert scale ranging from 1 (strongly agree) to 5 (strongly disagree). For the purpose of this trial, we will use a modified version comprised of 11 items (table 4). Removed items related to financial cost of physiotherapy care, diagnosis, time from physiotherapy referral to assessment, equipment available to the physiotherapist/assistant and compliance with physiotherapy. We removed these items because there is (1) no financial cost to patients associated with the intervention, (2) allied health assistants do not diagnose, (3) patients will not be aware of when they were referred to physiotherapy, (4) equipment available will not vary between the physiotherapist and the assistant and (5) compliance will be objectively measured. 


\begin{tabular}{cl}
\hline $\begin{array}{l}\text { Table } 4 \\
\text { Item } \\
\text { number }\end{array}$ & Modified patient satisfaction questionnaire \\
\hline 1 & $\begin{array}{l}\text { My therapists were good about explaining the } \\
\text { reason for my physiotherapy }\end{array}$ \\
\hline 2 & $\begin{array}{l}\text { The therapists were thorough in treating and } \\
\text { examining me }\end{array}$ \\
\hline 3 & $\begin{array}{l}\text { I had easy access to the therapists I needed } \\
\text { regarding feedback on my physiotherapy }\end{array}$ \\
\hline 4 & $\begin{array}{l}\text { My therapists treated me in a very friendly and } \\
\text { courteous manner }\end{array}$ \\
\hline 5 & $\begin{array}{l}\text { Those who provided my physiotherapy care } \\
\text { always took their time when they treated me }\end{array}$ \\
\hline 6 & $\begin{array}{l}\text { The therapists always acknowledged what I told } \\
\text { them }\end{array}$ \\
\hline 7 & $\begin{array}{l}\text { I had no doubts about the ability of the therapists } \\
\text { who treated me }\end{array}$ \\
\hline 10 & $\begin{array}{l}\text { The therapists who treated me had a genuine } \\
\text { interest in me as a person }\end{array}$ \\
\hline The therapists who treated me gave me respect \\
\hline 1
\end{tabular}

NB: The patient rates their agreement with each statement on a five-point Likert scale ranging from 1 (strongly agree) to 5 (strongly disagree).

\section{Demand}

The following measures will be used to determine the demand for the model of care and whether it is likely to be used:

- Qualitative interview with staff members to establish perceived demand for model of care (table 3).

- Proportion of eligible patients who participate.

\section{Implementation}

The following measures will be used to determine the extent to which the model of care is successfully delivered to intended participants:

- Qualitative interview with staff members to establish factors affecting implementation ease or difficulty (table 3).

- Time allied health assistant/physiotherapist spends with participant will be classified as either (1) direct contact activities (eg, providing therapy) or (2) indirect contact activities (eg, typing notes).

- Number of physiotherapy/allied health assistant occasions of service provided to each participant.

\section{Practicality}

The following measures will be used to determine whether the model of care can be carried out with intended participants using existing means, resources and circumstances without outside intervention:
- Qualitative interview with staff members to establish their perception of the positive and negative effects of the model of care on patients (table 3).

- Cost of acute physiotherapy service will be calculated using the time spent treating and managing patients with hip fracture and pay rates for allied health assistants and physiotherapists. ${ }^{3435}$

- Cost of acute patient care will be calculated using hospital costing data.

- Adverse events will include any incident of patient harm that is recorded in the health service incident reporting system. Patient harm events will be further classified as 'not related to the study', 'probably not related to the study', 'unlikely but possibly related' or 'probably related to the study' by an independent, medical academic. Harm events will also be classified as 'serious' or 'non-serious' (see https://www.fda. gov/Safety/MedWatch/HowToReport/ucm053087. htm).

\section{Secondary outcome measures}

The secondary outcomes for this trial will provide an estimate of the effect of allied health assistant care on patient and organisational outcomes.

\section{Patient outcomes}

Compliance with hip fracture clinical practice guidelines requires patients with hip fracture to be mobilised at least once a day. ${ }^{56}$ Therefore, the number of days that the patient mobilises during their acute hospital stay will be audited at discharge from acute hospital. For the purpose of this trial, mobilisation will refer to 'the process of re-establishing the ability to move between postures (eg, sit to stand), maintain an upright posture and to ambulate with increasing levels of complexity ${ }^{5}$ and will be measured on an ordinal scale: (1) step transfer out of bed, (2) standing or walking less than $5 \mathrm{~m}$ and (3) walking away from the bedside for a distance of at least $5 \mathrm{~m}$. The healthcare worker(s) who mobilise the patient will be recorded. Documented reasons for patients not mobilising, including the days on which mobilisation is medically contraindicated, will also be recorded. ${ }^{26-28}$

Discharge destination will be selected from the following list of possible destinations: (1) home, (2) relative/ friend's home, (3) residential care, (4) inpatient transition care programme, (5) subacute rehabilitation/ geriatric evaluation and management. Discharge destination will be audited from participant medical records at discharge from acute and subacute hospital.

Thirty-day hospital readmission will be used as a measure of safe patient care. Hospital readmission includes any unplanned readmission within 30 days of discharge from the health service (ie, readmission from private residence). Planned admissions (eg, for elective procedures) will be excluded. ${ }^{36} 37$

Recurrent and injurious falls during acute hospital stay will be recorded, where a fall is defined as "unintentionally coming to rest on the ground, floor or other 
lower level'. ${ }^{38}$ Falls will be further classified to reflect the degree of harm; falls that result in either the permanent or temporary loss of function will be classified as an injurious fall, while falls that result in no loss of function will be classified as a non-injurious fall. Fall rate will be expressed as falls per 1000 bed days and these data will be obtained from patient medical records and health service incident reporting system. ${ }^{39}$

Functional activity at discharge from acute hospital will be measured by assessing (1) the assistance they require to walk, transfer from a bed to a chair and go up/down a step and (2) their walking endurance on the day of discharge. ${ }^{40}$ Level of assistance required to transfer, walk and go up/down a step are classified on a 5-point ordinal scale from: 0-non-ambulant/fully dependent to 4independent. Level of walking endurance is classified on a 5-point ordinal scale from: $0-$ non-ambulant $/<5 \mathrm{~m}$ to 4-walked $\geq 100 \mathrm{~m}^{40}$

Patient demographic data, including age, gender, living arrangements, medical comorbidities, surgical approach and premorbid mobility, will also be routinely collected.

\section{Organisational outcomes}

Patient length of stay will be measured as the number of days from (1) patient admission to discharge from acute hospital (acute hospital length of stay) or (2) patient admission to discharge from subacute hospital (subacute length of stay). The length of stay will, therefore, be inclusive of the patient's time spent in both acute and subacute hospital, where applicable.

Cost of acute and subacute physiotherapy service will be calculated using the time spent treating and managing participants and pay rates for allied health assistant, physiotherapists. ${ }^{34}{ }^{35}$ Cost of acute and subacute patient care will be calculated using hospital costing data.

\section{Participant timeline}

Patients will be screened for eligibility and recruited into the study following initial physiotherapy postoperative assessment. Patients who meet the eligibility criteria and consent to participation in the trial will be randomised to either the experimental (allied health assistant) or comparison (physiotherapy) group. Participants will receive their allocated intervention for the entirety of their acute hospital admission. At discharge from acute hospital, outcomes relating to feasibility, compliance with daily mobilisation guidelines, discharge destination, falls and length of acute hospital stay will be audited from patient medical records, incident reporting systems and hospital costing data. Participant satisfaction surveys will also be completed at this time. Participants who discharge to subacute hospital will have the following additional outcome measures collected from their medical records and hospital costing data at discharge from subacute hospital: discharge destination, length of subacute hospital stay, cost of subacute physiotherapy service and cost of subacute patient care. Readmission in the 30-days following discharge from the health service (ie,

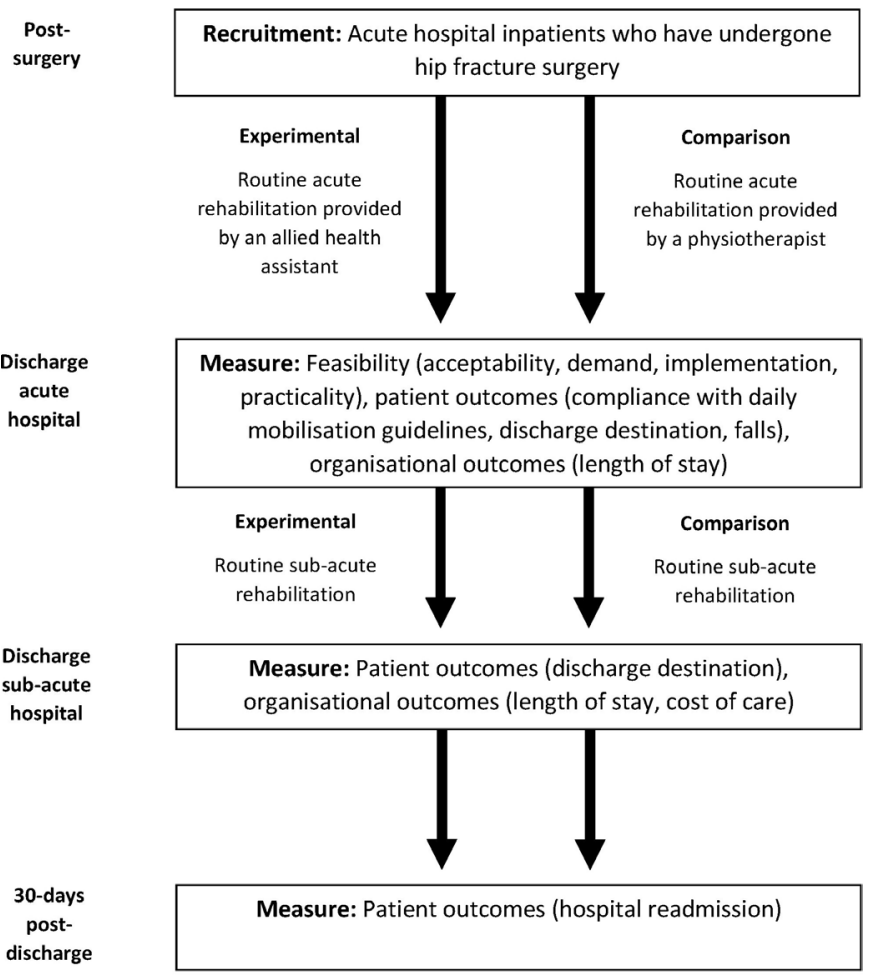

Figure 1 Participant timeline.

readmission from a private residence) will be audited for all participants. Please refer to figure 1 for an overview of the participant timeline.

\section{Data analysis}

Data monitoring and auditing

As this is a small, investigator-initiated feasibility trial, there is no external data monitoring committee. Audits are routinely completed by the approving ethics committee on an annual basis.

\section{Sample size estimation}

We aim to recruit 50 participants. While there are no clear guidelines on the sample size required for feasibility studies, this size is approximately three times larger than a comparable feasibility trial investigating an assistant model of care in an acute hospital setting and should enable the primary aim of feasibility to be addressed. ${ }^{1341}$

\section{Data analysis plan}

We will determine the feasibility of the model of care using a realist approach, which considers both quantitative and qualitative data in the decision-making process. ${ }^{42}$ Broadly, the allied health assistant model of care will be considered feasible if it meets the following criteria:

1. Both patients and staff report satisfaction with the new model of care.

2. Staff report demand for the new model of care.

3. At least $40 \%$ of eligible patients participate in the trial. Based on historical admission data, this will equate to a recruitment rate of approximately one new participant each week. 
4. Allied health assistants demonstrate the ability to provide routine acute physiotherapy rehabilitation for people with hip fracture.

5 . The new model of care is safe for people with hip fracture.

6. The cost of the new model of care is comparable to, or less than, the cost of the existing model of care.

To complement the quantitative data, we will consider the findings from qualitative data to provide further information about whether criteria have been met and to determine whether the model of care can be modified to improve feasibility.

Descriptive statistics will be used to describe the characteristics of the sample by group (means (SD), percentages and frequencies) as well as patient satisfaction, time physiotherapist/allied health assistant spends with patient, cost of physiotherapy service/patient care and adverse events. ${ }^{43}$ All analyses will be completed as randomised (ie, intention to treat analysis).

Compliance with daily mobilisation guidelines will be collected in the form of time-to-event data, and mobilisation rate ratios will be calculated using Cox proportional hazards regression to directly compare mobilisation rates in the experimental and comparison conditions. As patients can have multiple mobilisations and are not eligible for subsequent mobilisation until initial mobilisation has occurred, recurrent event data will be analysed via the Williams and Peterson Gap time survival model, with robust SEs to account for correlation within patients. In the survival analyses, discharge will be considered a censoring event. ${ }^{44}$ This equates to an assumption that data regarding mobilisation on days following discharge are missing at random (given timing of discharge). The appropriateness of this assumption will be checked in sensitivity analyses. No interim analyses will be conducted.

Length of stay will be analysed using survival analysis (time-to-discharge) with death as a competing risk. Sensitivity analysis will be conducted stratifying for complex admissions, where a complex admission is defined as any admission where a participant is readmitted to an acute hospital from a subacute hospital. Functional activity will be analysed using appropriate parametric or nonparametric tests, depending on the distribution of the data.

Dichotomous outcomes include discharge destination (home vs residential care), 30-day readmission (30-day readmission vs no readmission) and number of fallers (fall vs no falls). These will be analysed via logistic regression.

Qualitative analysis of transcripts will be undertaken by two investigators independently, using qualitative data management software. ${ }^{45}$ The deidentified transcripts will be read by each investigator and codes devised to represent the data. Codes will be reviewed and emerging themes will be developed inductively through a process of collapsing codes together and defining categories. ${ }^{46}$ Emergent themes will then be mapped onto the relevant areas of focus in Bowen's framework. ${ }^{22}$ Consensus between the investigators on the emerging themes and categories will be achieved through discussion.

\section{Limitations}

There are several limitations that must be acknowledged. First, we are excluding people with hip fracture with cognitive impairment and this limits the generalisability of our findings as approximately a third of patients with hip fracture have cognitive impairment. ${ }^{47}$ Participants will include patients who have undergone either hip joint replacement surgery or internal fixation with screws/ nails, which will ensure that results are generalisable to both types of surgery. However, due to the relatively low sample size, there is the possibility that type of surgery may be unevenly distributed, by chance, between intervention and usual care groups. This could introduce a confounding bias where trial results may be affected by the differences in postoperative pain levels between the two types of surgery. ${ }^{48}$ Another limitation of this trial is that neither participants nor staff members are blind to group allocation. ${ }^{49}$ Knowledge of group assignment can affect participants' responses to the intervention received and may lead to differential use of supplemental care by staff members (ie, cointervention bias). ${ }^{49}$ However, blinding of participants and healthcare staff is difficult in non-pharmacological trials and blinding the participant to the identity of the staff member (ie, physiotherapist vs allied health assistant) was deemed unethical by the reviewing ethics committee for our trial. ${ }^{50}$ There is also the risk of contamination between groups as both the intervention and usual care will be provided in parallel. As part of our feasibility assessment, we will be measuring the success of the implementation of the allied health assistant model of care (ie, occasions of service and time spent with patient), which will inform whether alternative study designs, such as cluster RCTs, are required to control for contamination. ${ }^{51}$ Last, prespecified progression criteria for determining feasibility can help to prevent biased post hoc cases for continuation to a larger trial, and the absence of such criteria in this trial is a possible limitation. ${ }^{52} 53$ However, there is limited guidance on how to establish these binary indicators for continuation and this can lead to ambiguous criteria. ${ }^{53}$ This approach can also lead to an overreliance on quantitative data when determining feasibility. ${ }^{53}$ Therefore, we have chosen to use a realist approach, where we will use both qualitative and quantitative data to establish "what is feasible and acceptable for whom and under what circumstances' ${ }^{43}$ (p294). A sufficient qualitative understanding will complement the quantitative findings and help us to determine the feasibility of the model of care. It may also help to explain our quantitative findings and inform how the model of care and/or trial design could be modified to improve feasibility. ${ }^{54}$

\section{Patient and public involvement statement}

Patients and public have not been involved in design of this study. Patients will be involved in determining 
the acceptability of allied health assistant care through completion of a satisfaction questionnaire.

\section{Ethics and dissemination}

Ethical approval was granted by the Peninsula Health human research ethics committee before the trial commenced (HREC/63 005/PH-2020). Due to inclusion criteria, participants will be competent to provide their own written consent to participate. The findings from this trial will be disseminated through peer-reviewed journal publications and conference presentations. Staff and patient participants will be informed of the study findings at the conclusion of the trial on request.

\section{Trial status}

Enrolment for the trial began in February 2021 and is still in progress. Data collection will continue until the target sample size is reached, expected April 2022.

\section{Twitter Nicholas F Taylor @EH_Research}

Contributors DAS, NFT, MC and TC designed the trial, led acquisition of funding, drafting and critical revision of the manuscript. PV contributed substantially as the trial coordinator, drafting and critical revision of the manuscript. YTW contributed as a research officer at one site and critical evaluation of the manuscript.

Funding This trial is supported by a 2020 Australian Physiotherapy AssociationPhysiotherapy Research Foundation Seeding Grant (no grant number). The funder will have no role in study design; collection management, analysis, and interpretation of data; writing of the report; or decision to submit the report for publication.

Competing interests None declared.

Patient consent for publication Not applicable.

Provenance and peer review Not commissioned; externally peer reviewed.

Supplemental material This content has been supplied by the author(s). It has not been vetted by BMJ Publishing Group Limited (BMJ) and may not have been peer-reviewed. Any opinions or recommendations discussed are solely those of the author(s) and are not endorsed by BMJ. BMJ disclaims all liability and responsibility arising from any reliance placed on the content. Where the content includes any translated material, BMJ does not warrant the accuracy and reliability of the translations (including but not limited to local regulations, clinical guidelines, terminology, drug names and drug dosages), and is not responsible for any error and/or omissions arising from translation and adaptation or otherwise.

Open access This is an open access article distributed in accordance with the Creative Commons Attribution Non Commercial (CC BY-NC 4.0) license, which permits others to distribute, remix, adapt, build upon this work non-commercially, and license their derivative works on different terms, provided the original work is properly cited, appropriate credit is given, any changes made indicated, and the use is non-commercial. See: http://creativecommons.org/licenses/by-nc/4.0/.

\section{ORCID iDs}

David A Snowdon http://orcid.org/0000-0003-2041-3120

Nicholas F Taylor http://orcid.org/0000-0001-9474-2504

\section{REFERENCES}

1 Watts JJ, Abimanyi-Ochom J, Sanders KM. Osteoporosis costing all Australians: a new burden of disease analysis - 2012 to 2022, 2013. Available: https://healthybonesaustralia.org.au/wp-content/uploads/ 2020/11/Burden-of-Disease-Analysis-2012-2022.pdf [Accessed 01 May 2021].

2 Beringer TRO, Clarke J, Elliott JRM, et al. Outcome following proximal femoral fracture in Northern Ireland. Ulster Med $\mathrm{J}$ 2006;75:200-6.

3 March LM, Cameron ID, Cumming RG. Mortality and morbidity after hip fracture: can evidence based clinical pathways make a difference? J Rhemuatol 2000;27:2227-31 https://pubmed.ncbi.nlm. nih.gov/10990238/
4 Koval KJ, Zuckerman JD. Functional recovery after fracture of the hip. J Bone Joint Surg Am 1994;76:751-8.

5 Australian and New Zealand hip fracture registry (ANZHFR) steering group. Australian and New Zealand guideline for hip fracture care: improving outcomes in hip fracture management of adults, 2014. Available: https://anzhfr.org/wp-content/uploads/2016/07/ANZGuideline-for-Hip-Fracture-Care.pdf [Accessed 01 May 2021].

6 National Clinical Guideline Centre (NICE). The management of hip fracture in adults, 2017. Available: https://www.nice.org.uk/guidance/ cg124/evidence/full-guideline-183081997

7 Snowdon DA, Leggat SG, Harding KE, et al. Direct supervision of physiotherapists improves compliance with clinical practice guidelines for patients with hip fracture: a controlled before-and-after study. Disabil Rehabil 2020;42:3825-32.

8 Kristensen PK, Thillemann TM, Søballe K, et al. Are process performance measures associated with clinical outcomes among patients with hip fractures? a population-based cohort study. Int $J$ Qual Health Care 2016;28:698-708.

9 Sheehan KJ, Goubar A, Almilaji O, et al. Discharge after hip fracture surgery by mobilisation timing: secondary analysis of the UK national hip fracture database. Age Ageing 2021;50:415-22.

10 Davenport SJ, Arnold M, Hua C, et al. Physical activity levels during acute inpatient admission after hip fracture are very low. Physiother Res Int 2015;20:174-81.

11 Kimmel LA, Liew SM, Sayer JM, et al. HIP4Hips (high intensity physiotherapy for hip fractures in the acute hospital setting): a randomised controlled trial. Med J Aust 2016;205:73-8.

12 Haas R, O'Brien L, Bowles K-A, et al. Health professionals' perceptions of the allied health role in the acute setting following hip and knee joint replacement surgery: a qualitative study. Disabil Rehabil 2020;42:93-101.

13 Salisbury LG, Merriweather JL, Walsh TS. The development and feasibility of a ward-based physiotherapy and nutritional rehabilitation package for people experiencing critical illness. Clin Rehabil 2010;24:489-500.

14 Shearer T, Guthrie S. Facilitating early activities of daily living retraining to prevent functional decline in older adults. Aust Occup Ther J 2013;60:319-25.

15 Conway J, Kearin M. The contribution of the patient support assistant to direct patient care: an exploration of nursing and PSA role perceptions. Contemp Nurse 2007;24:175-88.

16 Lizarondo L, Kumar S, Hyde L, et al. Allied health assistants and what they do: a systematic review of the literature. $J$ Multidiscip Healthc 2010;3:143-53.

17 Nancarrow S, Mackey $\mathrm{H}$. The introduction and evaluation of an occupational therapy assistant practitioner. Aust Occup Ther $J$ 2005;52:293-301.

18 Somerville L, Davis A, Elliott AL, et al. Building allied health workforce capacity: a strategic approach to workforce innovation. Aust Health Rev 2015;39:264-70.

19 Stanhope J, Pearce C, Role PC. Role, implementation, and effectiveness of advanced allied health assistants: a systematic review. J Multidiscip Healthc 2013;6:423-34.

20 Snowdon DA, Storr B, Davis A, et al. The effect of delegation of therapy to allied health assistants on patient and organisational outcomes: a systematic review and meta-analysis. BMC Health Serv Res 2020;20:491.

21 Knight K, Larner S, Waters K. Evaluation of the role of the rehabilitation assistant. Int J Ther Rehabil 2004;11:311-7.

22 Bowen DJ, Kreuter M, Spring B, et al. How we design feasibility studies. Am J Prev Med 2009;36:452-7.

23 Australian Bureau of Statistics. 2016 census Quickstats: Mornington Peninsula (S), 2017. Available: https://quickstats.censusdata. abs.gov.au/census_services/getproduct/census/2016/quickstat/ LGA25340 [Accessed 13 Sep 2021].

24 Department of Health \& Human Services. Mornington Peninsula (S), 2014. Available: https://www2.health.vic.gov.au/about/publications/ policiesandguidelines/Mornington\%20Peninsula\%20S [Accessed 13 Sep 2021].

25 Pfeiffer E. A short portable mental status questionnaire for the assessment of organic brain deficit in elderly patients. J Am Geriatr Soc 1975;23:433-41.

26 Kehlet H, Dahl JB, Anaesthesia DJB. Anaesthesia, surgery, and challenges in postoperative recovery. Lancet 2003;362:1921-8.

27 Kehlet H, Søballe K. Fast-track hip and knee replacement--what are the issues? Acta Orthop 2010;81:271-2.

28 Kehlet H. Fast-track hip and knee arthroplasty. Lancet 2013;381:1600-2.

29 Australian and New Zealand hip fracture registry. annual report, 2020. Available: https://anzhfr.org/wp-content/uploads/2020/09/ANZHFR2020-Annual-Report-FULL.pdf [Accessed 20 May 2021]. 
30 Department of Health. Supervision and delegation framework for allied health assistants, 2012. Available: https://www2.health.vic. gov.au/about/publications/policiesandguidelines/Supervision-anddelegation-framework-for-allied-health-assistants [Accessed 01 May 2021].

31 Peninsula Health. Allied health clinical supervision practice guideline, 2019. Available: https://www.peninsulahealth.org.au/wp-content/ uploads/Research-Report-2019.pdf

32 Krefting L. Rigor in qualitative research: the assessment of trustworthiness. Am J Occup Ther 1991;45:214-22.

33 Ampiah PK, Ahenkorah J, Karikari M, Dip MK. Patients' satisfaction with inpatient orthopedic physiotherapy services at a tertiary hospital in Ghana. J Patient Exp 2019;6:238-6.

34 Victorian Government. Allied health professionals (Victorian public health sector) single interest enterprise agreement 2016-2020, 2016. Available: https://www.vhia.com.au/wp-content/uploads/Bul-2630Attachment-C.pdf

35 Victorian Government. Victorian public health sector (health and allied services, managers and administrative workers) single interest enterprise agreement 2016-2020, 2016. Available: https://www. vic.gov.au/sites/default/files/2020-10/Victorian-Public-ServiceEnterprise-Agreement-2020.pdf

36 Fisher SR, Kuo Y-F, Sharma G, et al. Mobility after hospital discharge as a marker for 30-day readmission. J Gerontol A Biol Sci Med Sci 2013;68:805-10.

37 Kim SJ, Lee JH, Han B, et al. Effects of hospital-based physical therapy on hospital discharge outcomes among hospitalized older adults with community-acquired pneumonia and declining physical function. Aging Dis 2015;6:174-9.

38 Buchner DM, Hornbrook MC, Kutner NG, et al. Development of the common data base for the FICSIT trials. J Am Geriatr Soc 1993;41:297-308.

39 Hill A-M, Hoffmann T, Hill K, et al. Measuring falls events in acute hospitals-a comparison of three reporting methods to identify missing data in the hospital reporting system. J Am Geriatr Soc 2010;58:1347-52.

40 Vukomanović A, Popović Z, Durović A, et al. The effects of short-term preoperative physical therapy and education on early functional recovery of patients younger than 70 undergoing total hip arthroplasty. Vojnosanit Pregl 2008;65:291-7.
41 Leon AC, Davis LL, Kraemer HC. The role and interpretation of pilot studies in clinical research. J Psychiatr Res 2011;45:626-9.

42 Fletcher A, Jamal F, Moore G, et al. Realist complex intervention science: applying realist principles across all phases of the medical Research Council framework for developing and evaluating complex interventions. Evaluation 2016;22:286-303.

43 Lee EC, Whitehead AL, Jacques RM, et al. The statistical interpretation of pilot trials: should significance thresholds be reconsidered? BMC Med Res Methodol 2014;14:41.

44 Kelly PJ, Lim LL. Survival analysis for recurrent event data: an application to childhood infectious diseases. Stat Med 2000;19:13-33.

45 QSR international Pty LTD. NVivo qualitative data analysis software version 10, 2012. Available: https://www.qsrinternational.com/nvivoqualitative-data-analysis-software/home

46 Saldana J. The coding manual for qualitative researchers. 3rd edn. Thousand Oaks (CA): Sage, 2016.

47 Mundi S, Chaudhry H, Bhandari M. Systematic review on the inclusion of patients with cognitive impairment in hip fracture trials: a missed opportunity? Can J Surg 2014;57:E141-5.

48 Foss NB, Kristensen MT, Palm H, et al. Postoperative pain after hip fracture is procedure specific. Br J Anaesth 2009;102:111-6.

49 Schulz KF, Grimes DA. Blinding in randomised trials: hiding who got what. Lancet 2002;359:696-700.

50 Boutron I, Tubach F, Giraudeau B, et al. Blinding was judged more difficult to achieve and maintain in nonpharmacologic than pharmacologic trials. J Clin Epidemiol 2004;57:543-50.

51 Torgerson DJ. Contamination in trials: is cluster randomisation the answer? BMJ 2001;322:355.

52 El-Kotob R, Giangregorio LM. Pilot and feasibility studies in exercise, physical activity, or rehabilitation research. Pilot Feasibility Stud 2018;4:137.

53 Hallingberg B, Turley R, Segrott J, et al. Exploratory studies to decide whether and how to proceed with full-scale evaluations of public health interventions: a systematic review of guidance. Pilot Feasibility Stud 2018;4:104.

54 O'Cathain A, Hoddinott P, Lewin S, et al. Maximising the impact of qualitative research in feasibility studies for randomised controlled trials: guidance for researchers. Pilot Feasibility Stud 2015;1:32. 